\title{
Ethno Medicinal Value of Plants in Thanjavur District, Tamil Nadu, India
}

\author{
Kaliyamoorthy Jayakumar \\ Department of Botany, A.V.C College (Autonomous), Mannampandal 609 305, Tamilnadu, India \\ Tel.: +919965942672 \\ E-mail address: jk81botany@yahoo.com
}

\begin{abstract}
The present investigation has been carried out to find the ethno medicinal value of plants in Thanjuvur District of Tamil Nadu, India. This study of ethno medicinal value of plants and cure the various disease of around the Thanjuvur District. Ancient methods of treatment by ethno medicinal value of various types of trees, shrubs, herbs and underground modification such as root, stem, bark, leaves, flowers, fruits and seed. The ethno medicinal value of plants make grounded plant parts, and juices used to cure the various diseases like, cough, cold, asthma, eye disease, ulcer, jaundice, rheumatic arthritis, memory stimulants, wound healing and cardiovascular disease. We have identified and reported more than 38 species of medicinally important plants belonging to 25 families.
\end{abstract}

Keywords: Ethno medicine; ancient people; Medicinal Plants; Thanjavur District

\section{INTRODUCTION}

India is commonly called the Botanical Garden of the world, owing to her wealth of herbal medicines. India with its great topographic and climatic diversity has a very rich and diverse flora and fauna. The uses of plants as medicines have been practiced from an ancient time. From around 1500 B.C. Rig Veda is one of the important earliest available documents which emphasizes about herbal medicinal knowledge. Later on Indian herbalists such as Maharshi Charaka and Sushruta worked in searchof different herbal plant parts for different aliments of human body. Later on, it is reported that traditional healers use near about 2500 plant species and 100 species of plants serve as regular sources of medicine. World Health organization has stated that $80 \%$ of the world's population depends on traditional medicine for its primary health care and has become indispensable for its survival Since times immemorial, plants have been put to medicinal use by the traditional herbalists, Hakims, Vaidays, Ayurvedic practioners and the common man. Herbal medicine is the study and use of medicinal properties of plants. Therefore medicinal plants constitute precious resources for mankind. (Akgul, 2008 and Sinhababu and Banerjee, 2013).

Documentation of the indigenous knowledge through ethno-botanical studies is important for the conservation and utilization of biological resources (Muthu et al., 2006 and Macia et al., 2005). Therefore, determining the local names and indigenous uses of plants has significant potential societal benefits (Kargioglu, et al., 2008 and Jayakumar, 2013b). The 
present study investigated the plants traditionally used in the treatment of specific diseases, and the local names of these plants.

\section{MATERIALS AND METHODS}

Tamil Nadu is ethnobotanically very rich, having a wide variety of medicinal plants. With its (Cauvery) diverse topographical condition, the region is well situated for a range of medicinal plant species. Kumbakonam (Aduthurai) is located at $10.97^{\circ} \mathrm{N} 79.42^{\circ} \mathrm{E}$. It is situated $273 \mathrm{~km}(170 \mathrm{mi})$ south of Chennai, $96 \mathrm{~km}(60 \mathrm{mi})$ east of Tiruchirappalli, and about $40 \mathrm{~km}(25 \mathrm{mi})$ north-east of Thanjavur. It lies in the region called the "Old delta" which comprises the north-western taluks of Thanjavur district that have been naturally irrigated by the waters of the Cauvery and its tributaries for centuries in contrast to the "New Delta" comprising the southern taluks that were brought under irrigation by the construction of the Grand Anicut canal and the Vadavar canal in 1934. It has an average elevation of 26 meters $(85 \mathrm{ft})$. The town is bounded by two rivers, the Cauvery River on the north and Arasalar River on the south. Although the Cauvery delta is usually hot, the climate of Kumbakonam and other surrounding towns is generally healthy and moderate. Kumbakonam is cooler than Chennai, the capital of Tamil Nadu.

The maximum temperature in summer is about $40{ }^{\circ} \mathrm{C}(104 \mathrm{~F})$ while the minimum temperature is about $20^{\circ} \mathrm{C}(68 \mathrm{~F})$. Kumbakonam receives an annual rainfall of $114.78 \mathrm{~cm}$ (45.19 in) every year. The region is covered with mainly alluvial or black soil which is conducive for rice cultivation. Other crops grown in Aduthurai include mulberry, cereals and sugarcane. The town of Aduthurai is surrounded by extensive paddy fields. Methods of irrigation were considerably improved following the opening of the Mettur Dam in 1934. The fauna of the Cauvery Delta is limited to cattle and goats.

The town is situated at the western flank of the Kumbakonam-Shiyali ridge which runs along the Kollidam river basin separating the Ariyalur-Puducherry depression from the Nagapattinam depression. This granular ridge projects further eastwards penetrating the Puducherry depression and forms a hard layer of cretaceous rock underneath the sedimentary top soil. The climate of Aduthurai is similar to the climate prevailing in the rest of the Cauvery Delta. The average maximum temperature is $39.4{ }^{\circ} \mathrm{C}$ while the average minimum temperature is $32.8{ }^{\circ} \mathrm{C}$. The average annual rainfall is $1,125 \mathrm{~mm}$. The plants were collected with the help of traditional healers and the information regarding the use of plants were recorded in the field note books.

\section{1. Interviews with Local People}

A questionnaire was administered to the local people, through face to face interviews. The questionnaire was administered only to people who had knowledge of medical plants. During the interviews, demographic characteristics of the participants, and local names, used parts and preparation methods of the plants were recorded. In addition, the participants were asked to show the researchers these wild plants in the field. Then specimens of these plants were collected.

\section{2. Plant Materials}

Field study was carried out over a period of approximately Five month (2014). During this period, a totally calculated vascular plant specimens were collected. The plants were 
pressed in the field and prepared for identification. Plants were identified using the standard text, cambel of flora the names of plant families were listed in alphabetic order. After the taxon names were identified, instances of endemism and hazard categories (Ekim et al., 2000) were specified.

\section{3. Identification of Plants}

The information recorded was further ascertained or cross checked by consulting the beneficiary's villagers and other traditional physicians. The plant specimens were also identified according to different references concerning the medicinal plants of South India. The medicinal information given in this paper includes botanical term family local name parts used and their medicinal use.

\section{RESULTS AND DISCUSSION}

\section{List of Ethno medicinal Plants and its uses}

Species: Mimosa pudica L.

Family: Mimosaceae

Vernacular name: Thottavaadi

Organ: Whole plant

Uses: Decoction from the plant used to treat diabetes Decoction from the leaves used to cure

Cough and cold

Species: Vitex negundo L.

Family: Verbenaceae

Vernacular name: Karinotchi

Organ: root, stems, leaves, seeds and whole plant

Uses: The whole plant decoction is used to treat cough, fever and asthma. Roots tincture is used in rheumatism. Leaves are effective in gonorrheal epididymitis and as vermifuge. Smoke from the burning dried leaves relieves headache.

Species: Tinospora cordifolia. Miers

Family: Menispermaceae

Vernacular name: Amruthu or Chittamruthu

Organ: Root, stem

Uses: Decoction of the root and stems are used to treat diarrhea and dysentery. Stem made into a paste and applied externally to treat various skin ailments.

Species: Curcuma aromatica Salisb.

Family: Zingiberaceae

Vernacular name: Kasthoorimanjal

Organ: Tuber or rhizome

Uses: Dried rhizome is used against various skin diseases.

Species: Abrus precatorius L.

Family: Fabaceae

Vernacular name: Kunnikkuru

Organ: Roots, leaves and seeds 
Uses: leaf extract are externally is applied to treat itching and other skin diseases, paste of seeds applied to the affected area to treat stiffness of shoulder joint and paralysis. Roots decoction is used internally as abortifacient.

Species: Gmelina arborea Roxb.

Family: Verbenaceae

Vernacular name: Kumbil

Organ: Roots, stems, leaves, fruits

Uses: Decoction of the root is used to treat stomach ache, digestive, laxative etc., fruit and bark decoctions used to treat fever. Leaf paste is applied to forehead to relieve headache. Bark decoctions are bitter and used to treat fever.

Species: Aegle marmelos Corv.

Family: Rutaceae

Vernacular name: Koovalam

Organ: Root, stems, Leaves, fruits

Uses: Root bark is used to treat intermittent fever. The unripe fruit is an astringent, digestive stomachic and also used in diarrhea. Various parts of plants are used to relieve thirst, stomach pain, night fever, breast pain, Fruit decoction used for treatment of intestinal diseases.

Species: Glycosmis pentaphylla Correa.

Family: Rutaceae

Vernacular name: Kurumana

Organ: roots, stems, leaves or whole plant

Uses: Plant decoction is commonly used as a medicine to treat cough, rheumatism, anemia and jaundice. Decoction of roots is helpful in facial inflammation. Leaf juice is taken internally to cure fever and paste of leaves is applied externally to treat skin diseases.

Species: Tragia involucrata L.

Family: Euphorbiaceae

Vernacular name: Koduthuva or cherukoduthuva

Organ: Root and Fruit

Uses: Root decoctions are take internally by drunk is used as blood purifier. Paste from the root is applied externally to kill worms.

Species: Emblica officinalis Gaertn.

Family: Euphorbiaceae

Vernacular name: Nellikka

Organ: Roots, stems, leaves, flowers, dried fruits and seeds

Uses: Root and bark is astringent, decoctions from leaves are useful for ulcers in mouth, Fruit and flowers have a cooling effect when it mixed with water. Fruits are used for laxative and purgative and also for abundant growth of hair.

Species: Euphorbia hirta L.

Family: Euphorbiaceae

Vernacular name: Kuzhinakhapala

Organ: Whole plant 
Uses: Latex from the herb is a vermifuge. Juice from the plant is given to treat dysentery and colic, latex is applied to cure warts.

Species: Alpinia calcarata Rose.

Family: Marantaceae

Vernacular name: Chittaratha

Organ: Rhizomes and seeds

Uses: Seed decoction is used to treat diarrhea. Rhizome decoction as anti-inflammatory

Species: Jasminum grandiflorum L.

Family: Oleaceae

Vernacular name: Pichakam

Organ: Roots, flowers and whole plant

Uses: Whole plant extract is used externally to treat facial paralysis. Paste from the root is useful to cure ringworm disturbances. Flower petals extract is applied externally against skin diseases, headache.

Species: Eclipta alba Hossak.

Family: Asteraceae

Vernacular name: Kayyunni

Organ: roots, Leaves and whole plants

Uses: Leaf juice boiled with coconut oil is used for luxuriant black hair. Extract from the leaves cure skin diseases by external application.

Species: Centella asiatica (L.) Urban.

Family: Asteraceae

Vernacular name: Muthil

Organ: Leaves and whole plant

Uses: Extract from the leaves and whole plant are taken internally for improving memory

capacity and also used externally to cure head ache.

Species: Vernonia cineria Less.

Family: Asteraceae

Vernacular name: Poovamkuvunnal

Organ: Roots and leaves

Uses: Root decoction of it is useful in stomach ache and juice for cough and colic, leaf extract are used externally to cure various skin diseases.

Species: Elephentopus scamber L.

Family: Asteraceae

Vernacular name: Anachuvadi

Organ: Roots and leaves

Uses: Decoction of roots and leaves are used to cure dysentery and stomach pain. Roots and leaves pastes are applied externally to relief rheumatism.

Species: Hemidesmus indicus $\mathrm{R}$. Br.

Family: Asclepiadaceae

Vernacular name: Nannari

Organ: Root. 
Uses: Roots are made into a paste and applied externally to cure various skin diseases, decoction from the root as a good blood purifier and also cure stomach ache.

Species: Calotropis gigantea R. Cr.

Family: Asclepiadaceae

Vernacular name: Erik

Organ: Roots, leaves and flowers

Uses: Juice from the plant is used to cure piles. Root bark is made into a paste and applied to treat elephantiasis. Flower decoctions are good digestive and also cure stomachache.

Species: Cardiospermum halicacabum L.

Family: Sapindaceae

Vernacular name: Uzhinha

Organ: Root, Leaves and whole plant

Uses: Plant paste mixed with cow milk is useful in curing to treat swelling of legs. Leaf juices are taken internally to treat diabetes. They inhaling leaf juice relieves head ache.

Species: Tephrosia purpurea (L) Pers.

Family: Fabaceae

Vernacular name: Kaavaalai

Organ: Roots, leaves, seeds and whole plant

Uses: Decoction from the plant as a good blood purifier. Dried herb made as a paste and applied for the treatment of boils and pimples. Juices of leaves are beneficial in diabetes.

Species: Saraca indica L.

Family: Caesalpiniaceae

Vernacular name: Asokam

Organ: Flowers, seeds and stems

Uses: Decoction from the bark is an excellent remedy in suppressed menses and also treats menopause complaints. Powdered flowers mixed with water are used to treat dysentery.

Species: Vitis quandrangularis Wall.

Family: Vitaceae

Vernacular name: Changalam paranda

Organ: Roots, leaves and stem

Uses: Fresh shoot made into a pastes are applied for burns and wounds. Paste of the stem is applied over the fracture for best relief. Decoction of plant is applied against worms and to cure piles.

Species: Aerva lanata Juss.

Family: Amaranthaceae

Vernacular name: Cherula

Organ: Roots, leaves and flowers

Uses: Decoction of root and flower are used to treat kidney stone.

Species: Rauwolfia serpentina Benth. ex. Kurz.

Family: Apocynaceae

Vernacular name: Sarpagandhi

Organ: Roots and Leaves 
Uses: Root decoction reduces blood pressure. Extract of root is used for the treatment of diarrhea and intestinal disorder.

Species : Sida acuta Burm.

Family: Malvaceae

Vernacular name: Kurunthotty

Organ: Roots and Leaves

Uses: Leaves and roots extract is mixed with coconut oil and applied twice a day before bath for luxuriant hair.

Species: Aristolochia indica L.

Family: Aristolochiaceae

Vernacular name: Garudakkodi or Urithookki

Organ: Roots, stems, leaves, rhizomes and seeds

Uses: Root or rhizome decoction is used as gastric stimulant, and to treat skin diseases and also acts as a blood purifier. Leaf juice is used to treat cough.

Species: Adhatoda vasica Nees.

Family: Acanthaceae

Vernacular name: Adalodakam

Organ: Roots, leaves and flowers

Uses: Juice of leaves relieves cough. Root decoction is an expectorant and also used to treat fever.

Species: Andrographis paniculata Nees.

Family: Acanthaceae

Vernacular name: Nilaveppu or Kireyath

Organ: Whole plant

Uses: Whole plant is made into a paste and applied externally to skin for the treatment of various skin diseases. Root decoctions are used to treat stomachache. The juice is mixed with gingili oil and drunk, to cure fever and dysentery.

Species: Leucas aspera Spreng.

Family: Lamiaceae

Vernacular name: Thumba

Organ: Roots, leaves and flowers

Uses: Juice from the leaves is applied in the affected part to cure psoriasis; flower dot decoction is used to treat cold. The whole plant decoction is used to treat worm's induced effects.

Species: Cassia fistula L.

Family: Caesalpiniaceae

Vernacular name: Kanikonna

Organ: Roots, leaves, flowers and fruits

Uses: Juice of leaves is used to treat skin diseases; fruit extract is externally used to cure rheumatism. Root, bark, seeds and leaves are laxative.

Species: Asparagus racemosus Willd. 
Family: Asparagaceae

Vernacular name: Sataawaree

Organ: Tubers

Uses: Tuber consumption increases breast milk. It also used to treat ulcers. Tubers decoction mixed with milk used internally to cure diabetes.

Species: Cyperus rotundus L.

Family: Cyperaceae

Vernacular name: Muthanga

Organ: Roots

Uses: Decoction from the root is useful to treat intestinal problems, stomach pain. Root pastes are applied to cure wounds, sores etc.

Species: Strychnos nux vomica L.

Family: Loganiaceae

Vernacular name: Kanheeram

Organ: Stems and Leaves

Uses: Bark boiled with water and use externally to control the psoriasis by washing the affected area, two times daily. The extract from the tender leaves are used against tumors

Species: Mukuna pruvita (Bak.) Hook

Family: Leguminosae

Vernacular name: Naykurana

Organ: Seeds

Uses: The powdered seeds mixed with milk and taken internally cure sexual weakness

Species: Loranthus tomentosus L.

Family: Loranthaceae

Vernacular name: Ithilkanni

Organ: Whole plant

Uses: It has high medicinal properties based on the host. The decoction of plant is taken internally to cure the disorders like bleeding, yellow fever.

Species: Vinca rosea L.

Family: Apocynaceae

Vernacular name: Savamnaripovu or Nithyalakalyani

Organ: Roots and leaves

Uses: Leaf and root juices are used daily two times to cure diabetes. Leaves paste helps to relief muscle pain and wasp sting

Species: Phyllanthus amarus Schum. and Thonn.

Family: Euphorbiaceae

Vernacular name: Kizharnelli

Organ: Roots, stems, leaves, and Flowers

Uses: Whole plant decoction used to treat diabetes, and also used to cure cough and chest pain. The plant extract are used externally to treat wounds. 
Medicinal plants from forests provide health security to the millions of people depending upon traditional systems of medicine. In present study, we have reported 38 species belonging to 25 families. The information detailed about the botanical name of the plants and plant parts medicinal used. The records were documented from the local and tribal people of Tamil Nadu. The collected various species of plants were used to treat 27 types of diseases such as wound and related injuries, body sickness, diarrhoea, skin problems, body pain, knee problem, cough, cold, fever, asthma, kidney problem, tonic, chronic disorders, several aches, hair growth, stomach problems, ulcer, sore throat, leprosy, opthalmia, typhoid, urinary bladder and rheumatism in terms of the number of plants collected in Aduthurai, Thanjavur district of Tamil Nadu.

Ethno-medical practices are preferred largely because medicinal plants are less expensive, readily available and reliable, and they are considered to have fewer side effects than modern medicines. This study assessed the survey of ethno-medicinal plant species used by Aduthurai, Thanjavur district of Tamil Nadu (Jayakumar, 2013a and Sathees kannan et al., 2013).

\section{CONCLUSION}

This survey of traditional knowledge and utility of medicinal plants for the treatment of various ailments among people living in Aduthurai is still a major part of their life and culture. They use plants, weeds, fruit plants, vegetables, spices and ornamental plants as traditional medicine. Many plant species are used in the treatment of many diseases, including diabetes, hypertension, gastrointestinal diseases, respiratory diseases and hemorrhoids. Therefore, this type of work may assist ethno-botanical survey and also be used in treatments.

\section{References}

[1] Akgul, G. (2008). Local names and ethnobotanical features of some wild plants of Ç1ldır (Ardahan) and its vicinity. Herb J. Syst. Bot., 14: 75-88.

[2] Arijit Sinhababu and Arpita Banerjee. (2013). Ethno-botanical Study of Medicinal Plants Used by Tribals of Bankura Districts, West Bengal. Journal of Medicinal Plants Studies 3(1): 98-104.

[3] Ekim, T., Koyuncu, M., Vural, M., Duman, H., Aytac, Z., and Adiguzel, N. (2000). Red Data Book of Turkish Plants (Pteridophyta and Spermatophyta). Turkish Association for the Conservation of Nature, Ankara.

[4] Kaliyamoorthy Jayakumar, (2013a). Assessment and Day to Day Utilization of Medicinal Plants in Mayiladuthurai - Nagapattinam District of Tamil Nadu, India, International Journal of Modern Biology and Medicine, 4(1): 54-63.

[5] Kaliyamoorthy Jayakumar, (2013b). Traditional Medicinal Values of Adhatoda vasica International Journal of Traditional and Natural Medicines, 3(1): 26-31.

[6] Kargioglu, M., Cenkci, S., Serteser, A., Evliyaoglu, N., Konuk, M., Kok, M. S., and Bagci, Y. (2008). An ethnobotanical survey of inner-West Anatolia, Turkey. Hum. Ecol., 36: 763-777. 
[7] Macia, M. J., Garcia, E., and Vidaurre, P. J. (2005). An ethnobotanical survey of medicinal plants commercialized in the markets of La Paz and El Alto, Bolivia. $J$. Ethnopharmacol., 97: 337-350.

[8] Muthu, C., Ayyanar, M., Raja, N., Ignacimuthu, S. (2006). Medicinal plants used by traditional healers in Kancheepuram district of Tamil Nadu, India. J. Ethnobiol. Ethnomed., 2: 43-48.

[9] Nimri, L. F., Meqdam, M. M., and Alkofahi, A. (1999). Antibacterial activity of Jordanian medicinal plants. Pharmaceut. Biol., 37: 196-201.

[10] Sathees Kannan. T. M, Kaliyamoorthy Jayakumar, L. Baskaran, M. Rajesh, (2013). InVitro Studies on Cardiospermum halicacabum L. International Journal of Traditional and Natural Medicines, 3(1): 1-10. 